\title{
Closing the Gap: Increasing Community Mental Health Services in Rural Indiana
}

\author{
Kristi Schultz ${ }^{1}\left[\right.$ ] Sara Farmer ${ }^{2} \cdot$ Sam Harrell $^{3} \cdot$ Carol Hostetter $^{4}$
}

Received: 24 October 2019 / Accepted: 26 October 2020 / Published online: 1 January 2021

(c) Springer Science+Business Media, LLC, part of Springer Nature 2021

\begin{abstract}
Due to the significant need for mental health services in rural Martin County, IN and lack of providers, this study examined the current strengths of the community as well as the barriers preventing mental health service delivery. The goal of the study was to propose community-specific solutions to overcoming the barriers. Using a strengths-based approach (Saleeby in The strengths perspective in social work practice, Longman, White Plains, NY, 1992), the authors first sought to understand Martin County residents' current experiences with mental health services. Second, the authors sought to understand Martin County residents' opinions about church/mental health partnerships. As a result of this analysis, the authors comprised a list of feasible and sustainable recommendations for Martin County and similar rural areas that incorporate the strengths in the community, address their identified challenges, and thus created a model for mental health service provision that can be replicated in other rural communities with similar strengths as well as similar challenges.
\end{abstract}

Keywords Rural $\cdot$ Mental health services $\cdot$ Social work $\cdot$ Churches

\section{Introduction/Literature Review}

Martin County, IN rests in the picturesque valley of the White River in the craggy uplands of Southern Indiana. The county's rich woodlands and lush riverbed leave visitors refreshed in contrast to Indiana's more common terrain of flat corn fields. With its quaint population of 10,000 , residents express love for their rural home; however, with only 30 people per square mile, Martin County residents live without many necessary social services to meet their basic needs. Mental health services-for both wellness and illnessespecially lag in this county which lacks a hospital within its borders. Additionally, the community mental health center (CMHC) for the region has only three providers, all of whom

Kristi Schultz

kriscchu@indiana.edu

1 School of Medicine, Indiana University, 39 E 9th Street, Apt 504, Indianapolis, IN 46204, USA

2 CCB Counseling, Catholic Charities, 803 N. Monroe St., Bloomington, IN 47404, USA

3 School of Social Work, Portland State University, PO Box 751, Portland, OR 97207, USA

4 School of Social Work, Indiana University, 1127 E. Atwater Avenue, Bloomington, IN 47401, USA work part-time in Martin County. Gaps in social services tend to start young with Martin County residents, as the youth exhibit mental health concerns. Fifty-three percent of Martin County youth have watched others be bullied, 36\% do not share their personal struggles with others, $29 \%$ report high levels of anxiety, $57 \%$ have been physically or verbally abused, and 40\% have had suicidal thoughts (Get Schooled Tour 2018). These children then grow up and continue to stay in Martin County, unable to receive the services they desperately want and need.

The self-reported data of Martin County's youth reflects the mental health trends of the county's larger population in comparison to the rest of Indiana. In 2018, Martin County's ratio of population to mental health service providers was 5110:1, while Indiana's average was 670:1. Additionally, the child abuse and neglect rate per 1000 children was 31.5 compared to Indiana's average of 17.2 (Indiana Youth Institute 2020). Risk factors that explain the higher numbers for rural families do not seem to be that different from risk factors in urban settings, according to Walsh and Mattingly (2012). The explanation is the lack of access to resources. Walsh and Mattingly state, "Given the climate of limited resources, it becomes more challenging to meet the many needs of families. Many of these challenges are exacerbated for rural communities, which also confront fewer qualified 
caseworkers, lack of transportation, and longer driving distances to services" 2012, (p. 3).

Martin County's heightened mental health needs coupled with its paucity of mental health services follows the pattern of many rural areas in the United States (US). Heflin and Miller (2012) demonstrate that rural areas like Martin County have higher levels of unmet and often complex social service needs than in metropolitan areas. These needs are often due to circumstances unique to the rural environment, such as a greater percentage of elderly individuals with increasing needs or the stress caused by economic downturns within the agricultural community (Bolin et al. 2015). Rural culture can also create unique barriers to mental health care, as residents often laud a "fix it yourself" mentality, as well as a wariness of outsiders that causes them to bypass services-especially on sensitive and personal matters (Daley 2015). Additionally, over $85 \%$ of US mental health provider shortage areas are in rural locations (Keeler et al. 2018).These shortages, which stem from a mixture of factors including a lack of cultural competence, competitive medical reimbursement, and declining infrastructure (Rural Health 2020), ultimately leave individuals with complex needs without access to the care they need.

Due to the unavailability of traditional services or stigma in using them, many rural residents turn to informal networks for mental health support (Daley 2015). Even when formal services may be available, they often do not take into account individual circumstances, environments, or expectations (McPherson et al. 2014). In 2014, 29\% or 65 million people in the US provided care for a chronically ill/disabled/ aging family member or friend. The field of nursing demonstrates that (1) the number of people acting as informal caregivers is growing; (2) the contribution informal caregivers make is crucial for sustainable health services; and (3) caregivers find working with health and social services problematic (McPherson et al. 2014). Voss (1996) showed that $80 \%$ of people who seek help for mental health problems first use informal community networks, while fewer than $20 \%$ go to a professional mental health worker-demonstrating a general unwillingness to use CMHCs. As Alford et al. (2012) point out, rural communities teem with diverse people with differing needs, assets, strengths, and weaknesses. Rural communities are not monolithic, and one size does not fit all in service provision. Positive collaboration must occur between formal and informal care providers, as well as empowerment of informal providers.

This interdependence between formal and informal care networks presents a rich opportunity for mental health expansion in rural communities. Rural mental health service providers have the opportunity to not only implement traditional strategies for rural mental health needs, but also to formulate unique solutions that fit unique rural communities. In doing so, mental health providers must depend on traditional as well as innovative solutions to providing mental health services. There is a rich history of rural grassroots organizing including mobilization towards therapeutic cultures and communities in rural areas (Olson 2011).

In examining the literature and the rural nature of Martin County, the authors followed a hypothesis that due to the geographical density of churches per capita in Martin County, churches may serve as a viable partner for enhancing mental health service delivery. Sun (2011) found a connection between perception of the availability of services and church attendance in older adults. Collaboration with churches has been a successful model to increase prevention and interventions in remote rural spaces in Kenya (Puffer et al. 2016). Although there are primarily Christian faithbased communities, the potential in the church community is rich in Martin County with more than 20 churches in its region. This information inspired further examination into ways to expand mental health services within church communities. Thus, this study sought to first understand people's current experiences with mental health services, and second, to understand people's opinions about church/mental health partnerships.

\section{Methods}

This study implemented a community-based, participatory framework (Baffour 2011; Strand et al. 2003) to collaborate with Martin County stakeholders and residents through surveys, focus groups, and key informant interviews. This community-based, participatory framework builds capacity within the community based on its existing infrastructure and resources, while also surveying attitudes on new mental health service implementation ideas informed by the research.

\section{Study Design}

Using both a reputational approach (Daley 2015) and a community-based participatory research framework (Baffour 2011; Strand et al. 2003), this study utilized Martin County community members' expertise on their own resources, wants, and needs. Through key informant interviews, partnerships with local agencies, and community surveys, solutions centered on mutual goals. This project gathered quantitative and qualitative data through the use of a mixedmethods approach (Faulkner and Faulkner 2018). Quantitative data were collected through a community survey, while qualitative data were derived from transcription and coding of themes found in community focus groups and key informant interviews. This study recruited participants $(\mathrm{N}=82)$ using non-probability sampling methods - specifically, purposive and snowball sampling through local churches and 
community agencies. Paper copies of the survey were also provided at focus groups, in case participants had not previously completed it.

\section{Survey Participants}

\section{Survey Instrument}

The survey instrument created for this study contains 33 items, including single response questions, multi-response questions, as well as Likert Scale response questions (see Appendix A). The topics of these items include demographics, previous experience and satisfaction with mental health services inside and outside Martin County, barriers to accessing mental health services, and likelihood of engagement with supplementary mental health service delivery models linked with churches. Survey questions were informed by Voss's (1996) list of potential churchmental health partnerships. These included: (a) provider identification/approval by church network, (b) counseling networks utilizing local churches, (c) Christian counseling centers, (d) education and enrichment activities (teach coping skills in church programming), (e) support groups, (f) lay counseling, (g) volunteer workers with the chronically mentally ill, and (h) clergy collaboration with local mental health practitioners.

The survey took 5-10 min to complete. Internal review board-approved flyers advertising the study and survey link were posted in community spaces in Martin County, as well as distributed electronically via organizational listservs, church communications, social media outlets, and email. The online survey provided a separate link for respondents to provide their contact information if interested in participating in a follow-up focus group. In addition to the online survey, paper copies were provided for local churches and organizations to distribute and were picked up at a specified date by the research team, though this method yielded no completed surveys. The research team distributed paper copies during open hours at a local food pantry and gathered completed responses. Data analysis was conducted with IBM SPSS 26 and includes descriptive statistics, as well as bivariate and multivariate analyses to determine differences between groups (Table 1).

\section{Focus Groups}

The research team conducted two focus groups $(\mathrm{N}=7$, $\mathrm{N}=4$ ) to explore and discuss survey findings. Participants in the groups were recruited via the contact information they elected to provide (voluntary) after completing the survey as well as through word of mouth recruitment at focus group locations. If participants at the focus groups had not previously completed the survey, they were given a paper copy
Table 1 Selected sample demographics $(\mathrm{N}=82)$

\begin{tabular}{|c|c|c|}
\hline Demographic & $n$ & $\%$ \\
\hline \multicolumn{3}{|l|}{ Gender } \\
\hline Female & 67 & 81.7 \\
\hline Male & 15 & 18.3 \\
\hline \multicolumn{3}{|l|}{ Age } \\
\hline $18-25$ & 7 & 8.5 \\
\hline $26-39$ & 22 & 26.8 \\
\hline $40-65$ & 45 & 54.9 \\
\hline $65+$ & 8 & 9.8 \\
\hline \multicolumn{3}{|l|}{ Race } \\
\hline White & 80 & 97.6 \\
\hline Person of color & 2 & 2.4 \\
\hline \multicolumn{3}{|l|}{ Highest attained academic level ${ }^{\mathrm{a}}$} \\
\hline High school diploma/GED & 14 & 17.1 \\
\hline Some college/trade school & 13 & 15.9 \\
\hline Associate degree & 12 & 14.6 \\
\hline Bachelor's degree & 14 & 17.1 \\
\hline Graduate/professional degree & 27 & 32.9 \\
\hline \multicolumn{3}{|l|}{ Annual household income ${ }^{a}$} \\
\hline$\$ 0-\$ 50,000$ & 19 & 23.2 \\
\hline$\$ 50,001-\$ 80.000$ & 16 & 19.5 \\
\hline$\$ 80,001-\$ 100,000$ & 18 & 22 \\
\hline Over $\$ 100,000$ & 21 & 25.6 \\
\hline \multicolumn{3}{|l|}{ Member of the clergy ${ }^{\mathrm{a}}$} \\
\hline Yes & 5 & 6.1 \\
\hline No & 76 & 92.7 \\
\hline \multicolumn{3}{|l|}{ Frequency of church attendance ${ }^{a}$} \\
\hline Never & 9 & 11 \\
\hline Few times a year & 16 & 19.5 \\
\hline Once a month & 4 & 4.9 \\
\hline Few times per month & 11 & 13.4 \\
\hline Once a week & 37 & 45.1 \\
\hline
\end{tabular}

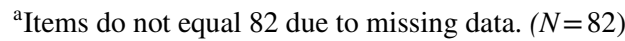

to complete and turn in at their convenience. The groups were audio-recorded using Kaltura Software after gaining informed consent from each participant. Audio recordings were permanently deleted after being transcribed for coding and analysis. All participants' names and sensitive information were redacted during transcription to retain their confidentiality; however, the participants of the focus groups inhabited a variety of community roles, such as health and social service providers, volunteers, church members, and those holding local civic/political positions. The first group consisted of four men and three women, with the second group consisting of four women. All focus group participants were legal adults and their ages ranged from 30 to 80 years old.

These groups were held within the community and guided by a set of questions to discuss the mental health service modalities most favored by survey respondents (see AppendixB ). Focus groups were led by the research facilitators and followed a semi-structured format, although further theme 
exploration expanded beyond the scope of the preset questions. The focus groups were held in accessible community spaces and lasted approximately an hour and a half. Focus group discourse was transcribed, coded, and analyzed for themes using a grounded theory framework (Keesler 2014; Glasser and Strauss 1967).

\section{Key Informant Interviews}

Key informant interviews were conducted by researchers prior to the creation of the survey and focus groups to gather broad knowledge of the Martin County community and the state of mental health services within the county. These interviews were informal in nature, although details noted were taken with permission of the informant. Researchers selected informants based upon a reputational approach (Daley 2015) and they represented various roles within the community such as health and social service providers, volunteers, church members, and those holding local civic/political positions. Information gathered from these interviews provided researchers with knowledge about the community and resources currently available, which helped to guide future interactions with the community, as well as the creation of survey questions.

\section{Results}

\section{Survey}

Survey results provided information on community members' experience with mental health services, willingness to seek help, and reactions specifically to church-based mental health interventions. These results revealed information on residents' perceptions of mental health service delivery and its barriers.

\section{Quality of Services and Barriers to Services}

In order to address the research question pertaining to individuals' opinions on church/mental health partnerships, the survey collected information about perceived satisfaction with previous mental health service use, as well as barriers to potential use. As shown in Table 2, 28\% (23 respondents) of the total sample have previously engaged with mental health services, with 20 reporting these services were located outside of Martin County. About 54\% (13 respondents) rated their satisfaction a four or higher on a scale of 1 to 5 . Only $8.4 \%$ ( 2 respondents) rated their satisfaction with the distance they had to travel to receive these services as a 4 or higher. This indicates respondents were satisfied with the quality of services they received but were dissatisfied with how far they had to travel for them.
Table 2 Experiences of those who previously engaged in mental health services $(\mathrm{N}=23)$

\begin{tabular}{lll}
\hline Item & $n$ & $\%$ \\
\hline Services were within martin county, IN & & \\
$\quad$ Yes & 3 & 13 \\
No & 20 & 87 \\
Quality of services & & \\
Satisfied/Highly Satisfied & 13 & 54.2 \\
Neutral & 5 & 20.8 \\
Not Satisfied & 6 & 25 \\
Distance traveled to receive services & & \\
Satisfied/Highly Satisfied & 2 & 8.4 \\
$\quad$ Neutral & 5 & 20.8 \\
Not Satisfied & 17 & 70.9 \\
\hline
\end{tabular}

Table 3 Perceived barriers to mental health services $(\mathrm{N}=82)$

\begin{tabular}{lll}
\hline Barrier & $n$ & $\%$ \\
\hline Availability of services & & \\
Barrier/Significant Barrier & 63 & 76.8 \\
Neutral & 9 & 11 \\
Not a Barrier & 10 & 12.2 \\
Knowledge of where to receive services & & \\
Barrier/Significant Barrier & 45 & 54.8 \\
Neutral & 17 & 20.7 \\
Not a Barrier & 20 & 24.4 \\
Financial means & & \\
Barrier/Significant Barrier & 44 & 53.6 \\
Neutral & 12 & 14.6 \\
Not a Barrier & 26 & 31.7 \\
\hline
\end{tabular}

\section{Barriers}

Use of descriptive analysis highlights clear barriers to receiving mental health services in Martin County, as displayed in Table 3. Availability of services was rated either as a barrier or significant barrier by $76.8 \%$ of the sample, along with knowledge of where to go to receive services (54.8\%), and financial means to receive services (53.6\%).

An independent samples t-test was utilized to gauge significant differences between genders in relation to the three aforementioned barriers, as displayed in Table 4. For the three key barriers (availability, knowledge of location, and financial means for services), the female group had a slightly higher mean, indicating this group identified these items as more of a barrier; however, the p-values for each test indicate no significant differences between gender groups on their perceptions of barriers. 
Table 4 Independent t-test comparing gender differences for selected barriers

\begin{tabular}{cllll}
\hline Barrier & Mean(SD) & $\begin{array}{l}\text { Mean Differ- } \\
\text { ence }\end{array}$ & Sig (2-tailed) \\
\hline $\begin{array}{c}\text { Avail- } \\
\text { ability of } \\
\text { services }\end{array}$ & $\begin{array}{l}\text { Female } \\
\mathrm{n}=67\end{array}$ & $\begin{array}{l}\text { Male } \\
\mathrm{n}=15\end{array}$ & 0.229 & 0.51 \\
$\begin{array}{c}\text { Financial } \\
\text { means }\end{array}$ & $\begin{array}{l}\text { Female } \\
\mathrm{n}=67\end{array}$ & $\begin{array}{l}3.80(0.94) \\
\mathrm{n}=15\end{array}$ & 0.293 & \\
& $3.45(1.58)$ & $3.20(1.37)$ & & \\
& & \\
$\begin{array}{c}\text { Knowledge } \\
\text { of where } \\
\text { to receive }\end{array}$ & $\mathrm{n}=67$ & $\mathrm{n}=51$ & \\
service & $3.45(1.58)$ & $3.20(1.37)$ & & 0.170 \\
\hline
\end{tabular}

\section{Church-based/Mental Health Service Delivery Options}

In order to address the research question regarding individuals' opinions on church/mental health partnerships, a portion of the survey presented various alternatives (Voss 1996) to the respondents and used a Likert Scale to measure their likeliness to utilize the presented service. Descriptive statistical analysis of the Church-based/Mental Health Partnerships section highlights the top respondent-identified church/mental health partnership options. The Likert Scale responses have since been condensed into three categories: Likely/ Extremely Likely, Neutral, and Unlikely (which encapsulates unlikely and extremely unlikely). The first modality - a mental health counselor located outside of Martin County referred by a trusted pastor/minister - was rated a 4 or higher (likely to extremely likely to use) by $59.8 \%$ of respondents. Meeting with a counselor from outside Martin County, but in a local church was rated a 4 or higher by half of the respondents. Responses to the other options are included in Table 5 below, however general opinions were mixed.

\section{Focus Groups}

The results of the two focus groups enriched the survey data by providing context and depth to the numbers (Faulkner and Faulkner 2018). The first focus group $(\mathrm{N}=7)$ consisted of people mostly familiar with each other and conversation flowed easily. This group revealed that church-based services were helpful for people who already attended church; however, they reported that many Martin County residents do not feel comfortable attending church. For this population, services based in church-communities would create an added barrier. The second focus group $(\mathrm{N}=4)$ consisted of human services professionals. This group revealed the shortage of providers, travel distance required for mental health services, and the overwhelming stigma attached to issues of mental health in Martin County.

Focus group participants responded via paper chat to the four most-preferred service modalities as identified by the
Table 5 Likeliness to utilize church/mental health partnerships

\begin{tabular}{lcc}
\hline Option & $n$ & $\%$ \\
\hline Mental health counselor located outside the county but referred by trusted clergy-member & \\
Likely/Extremely Likely & 49 & 59.8 \\
Neutral & 22 & 26.8 \\
Unlikely & 11 & 13.4 \\
Counselor is from outside the county but meets with you in local church & \\
Likely/Extremely Likely & 41 & 50 \\
Neutral & 25 & 20.5 \\
Unlikely & 16 & 19.6 \\
Counselor who works with you and trusted clergy-member in the county & & \\
Likely/Extremely Likely & 38 & 46.3 \\
Neutral & 20 & 24.4 \\
Unlikely & 24 & 29.3 \\
Bible study group that teaches mental health/coping skills & & \\
Likely/Extremely Likely & 37 & 45.1 \\
Neutral & 21 & 25.6 \\
Unlikely & 24 & 29.3 \\
Counselor on staff at local church & & \\
Likely/Extremely Likely & & \\
Neutral & 31 & 37.8 \\
Unlikely & 24 & 29.3 \\
Counselor you meet with via telehealth in a private space in a local church & 27 & 32.9 \\
Likely/Extremely Likely & & 30.5 \\
Neutral & 25 & 23.2 \\
Unlikely & 19 & 46.4 \\
\hline
\end{tabular}


survey (their written comments are included in Appendix C). Four pieces of large poster paper were placed throughout the room, each listing one of the identified service modalities: meet with a self-help group with Martin County residents, meet with a counselor outside Martin County referred by a pastor/church, meet with a counselor via internet within a church space, meet with a counselor from outside the county but within a church space in Martin County. Participants circulated past each paper, offering feedback, thoughts, and suggestions for each of the modalities.

\section{Discussion}

\section{Interpretations}

Survey data, interviews, and focus groups are in congruence that mental health struggles in Martin County are often generational and untreated. Focus group data has been included here to enrich the data and provide examples of themes. The data resoundingly identified four pressing mental health issues in the Martin County community: substance use, childhood trauma, suicidal ideation, and depression/anxiety. Despite these challenges, the singular community mental health treatment center in Martin County is underutilized. Two key themes defined Martin County residents' needs with regard to mental health services: trust and awareness. While the identified barriers to treatment may influence the use of the CMHC, trust of the staff and awareness of services may also have an impact on service use.

\section{Trust}

Mental health ethics prohibit dual relationships whenever they can be avoided (NASW 2019). However, Brocious et al. (2013) destigmatize dual relationships in rural social work and instead illustrate its assets, such as trust. A rural mental health worker's dual relationships can be a double-edged sword. On the one hand, dual relationships provide trust in a rural community. On the other hand, this can often be a barrier-especially in mental health treatment (Edwards et al. 2009; Humble et al. 2013; Waltman 2011). In order to use the strength of a dual relationship, a trusted mental health worker who lives in the community can be an asset for referring residents to mental health treatment provided by someone unknown to the client.

Survey results revealed that $60 \%$ of respondents wanted to meet with a counselor who came from outside of Martin County but was referred to them by a trusted pastor. In contrast, only $38 \%$ of respondents were comfortable with that person being on staff at the church. Only $37 \%$ wanted to be in a self-help group with their Martin County peers. This statistic was overwhelmingly corroborated in focus group discussion: people want to be treated by a professional known by someone they trust; however, they do not want that person to be from Martin County. Additionally, the survey revealed that people who were able to drive 60-90 min for services were pleased with their treatment and the anonymity provided by distance. However - as one might expect - this tremendous burden of time, transportation, and finances is insurmountable for many in the county. A focus group participant said, "Outside people coming in that don't know your history, that don't know your people, don't know anything about you. Way safer." A strength of this finding is that the community's preference to be served by an outside mental health provider increases their pool of providers. Use of services will likely increase if that provider is recommended by trusted community members.

\section{Awareness}

Data clearly revealed that residents were unaware of the resources located in their community. Survey results demonstrated that $55 \%$ of respondents felt that not knowing where to go or what services are available posed a significant barrier to their seeking services. This was observed through both quantitative and qualitative data. Well-connected key informants and focus group participants regularly discussed confusion as to the services provided by the CMHC as well as their days/hours of business. One focus group participant connected to a large church congregation expressed this: “And just like this lady, she didn't know what to do. She just came to the church and she was just wandering around town because she'd been battered [sic], she didn't know where to go, she needed to get away, and she found an open door, come in and found the janitor. That's just cause she didn't know what to do...If it's available and they don't know it, it's worthless."

\section{Community Recommendations}

This study resulted in four concrete recommendations informed by the data collected from residents, the strengths of the community (Saleeby 1992), and the feasibility for implementation. These four recommendations-a community-based resource guide, place-based services, university partnerships, and a hybrid telehealth model - were presented as the starting points around which a community-based task force could form. The task force would be a conduit for implementing the identified strategies and would consist of interested community members holding various roles in Martin County. The principal researchers would initially facilitate the task force, transitioning leadership to community members as interest arose. The task force would be egalitarian in leadership with goals and action steps decided by the group and reported through monthly meetings and 
email check-ins. The task force sought to be inclusive to all and did not require specific professions, prior knowledge, or community roles to join; however, researchers did seek to extend direct invitation to local health and social service providers. Thus, the community-driven task force provides grassroots organizing on behalf of the community's own social-ecological mental health needs (Castillo et al. 2019).

\section{Community-Based Resource Guide}

Qualitative and quantitative responses throughout this project emphasized that lack of knowledge of available mental health services - either inside or outside the county - presented a significant barrier to accessing treatment. While there are all-encompassing social service resource guides currently available to the residents of Martin County, they are not county-specific, well-known to the public, and lack community members' specific endorsements. This study suggests that residents of Martin County may be more willing to utilize the services recommended by individuals they trust from their community at large. Therefore, in an effort to address the trust desired by the community as well as increase the awareness of county-specific mental health services, community-based asset mapping (Griffin and Farris 2010) and the subsequent creation of a highly accessible resource guide are recommended.

Community asset-mapping is crucial for engaging the larger Martin County community and will allow individuals to map positive assets of individuals, organizations, and institutions within the county (Griffin and Farris 2010). By making a concerted effort to engage as much of the county's residents in the mapping of county resources, it is also possible that previously unknown sources of mental health services or support may be uncovered and increase their capacity to serve the community (Griffin and Farris 2010). Based on the themes extrapolated from this study, there is great potential for individuals in Martin County to have more positive views of mental health services when they are presented in a format that emphasizes their peers' recommendations. As a result of community asset mapping, various forms of media must be created to publicize the community asset map. These media may include full print resource guides for distribution at major community gathering places, online graphics or guides easily shared on social media, websites, and email, as well as more convenience media, such as flyers, fridge magnets, or pocket guides.

\section{Place-Based Service}

The dominant physicians' setting model for mental healthcare requires individuals to go to a designated location (e.g., a CMHC) to meet with a specialist. This creates barriers such as transportation to the clinic and stigma for entering a building that may be labeled negatively by the community (Kazdin 2017). These barriers, stigma especially, are reflected in Martin County's underutilization of their CMHC, which serves a large number of individuals courtordered through Community Corrections or the Department of Child Services. The stigma around the center and treatment may contribute to disuse of the resources that are located in-county. Therefore, finding ways to move mental health services outside of the brick-and-mortar clinic are necessary to decrease the stigma of treatment and meet clients where they are, both mentally and geographically.

The implementation of task-sharing, which seeks to unite and strengthen the limited number of providers (Hoeft et al. 2018), within Martin County may take many appearances. One method may be to install licensed therapists or behavioral health professionals in primary care provider offices (Hoeft et al. 2018) so that individuals experience decreased stigma as it appears superficially that they are making a routine medical appointment. Introducing treatment interventions in everyday, unconventional settings may also be feasible within Martin County as it would decrease the stigma of attending a clinic appointment. This delivery method seeks to place individuals who could provide treatment, service screening, and psychoeducation in everyday settings that county residents may already frequent for various reasons (Kazdin 2017). In Martin County, a setting such as a public library, church, or community center, may provide the amount of anonymity residents need while still being accessible. A community mental health worker may be stationed at these locations at various days/times, so individuals can seek out their services.

\section{University Partnerships}

Though Martin County finds itself excised from a central city hub, it has the unique strength of six universities with counseling/social services departments within $90 \mathrm{~min}$ of its center. The authors recommend Martin County provide the infrastructure and organizational culture to position itself as a hub for rural mental health student internships. Student interns/residents seek rural placements because of the vast array of experiences and generalist training they are exposed to, rather than a niche specialty. When well-supported, these rural placements have the potential to become coveted positions (Kitchener et al. 2015). Further, interns/residents are more likely to serve in rural areas after they have had experience there (Clark et al. 2013).

The umbrella mental health task force would form a committee that connects Martin County to the universities to place teams of intern/resident students in community spaces to provide place-based services. Focus group participants expressed a great desire for mental health care providers in their criminal justice system, schools, and other community 
locations. With the growing need for field placements in counseling, social work and other human services programs, this recommendation provides a vibrant synchronicity. Additionally, since students placed in rural areas are more likely to serve in rural areas (Kitchener et al. 2015), this increases the mental health service capacity for the future.

\section{Telehealth - A Hybrid Model}

Telehealth continues to rise in popularity among rural populations as a way to bridge the gap in services, especially as COVID-19 has radically expanded its access. Cunningham and Merwe (2009) discuss the use of telehealth both for medical training as well as distance continuing education units (CEUs). Their model addresses three key problems in rural areas: (1) increasing the number of service providers by enhancing education opportunities and knowledge of evidence-based practice; (2) extending the reach of services provided by the current workforce; and (3) increasing job satisfaction in current providers through support, quality of life, continuing education, and increased skills. In addition to travel for services, travel distance for students is also a barrier. Rural communities like Martin County can be isolated from mentors, supervisors, professional peers, and specialists. Therefore, the development of a virtual mentoring network could increase exposure of students in underserved areas to $\mathrm{MH}$ professionals to address recruitment and retention of individuals who are interested in providing mental health services in rural locations (Keeler et al. 2018).

Telehealth can encompass many different modalities, including phone calls, video conferencing, mobile apps, text messaging, etc. In order to fit the Martin County paradox of trust and anonymity, the authors propose a hybrid model for telehealth. One model could include residents traveling to the brick-and-mortar office of a telehealth provider within the region in order to establish a relationship. For those residents able to travel, they would continue face-to-face meetings until an adequate level of rapport has been established. At that point, the resident can transition to a form of telehealth that fits their needs (for example, biweekly faceto-face meetings alternating with telehealth meetings). This model lessens the transportation barrier while still maintaining a level of trust and personal connection. A second model could include Martin County contracting with a regional telehealth provider who travels to Martin County for faceto-face meetings to build rapport, then transitioning to telehealth as in model one.

\section{Implications for Rural Community Mental Health Practice}

\section{Strengths}

This study matched certain census demographic data. According to the U.S. Census Bureau in 2018, 97.9\% of Martin County residents identify as white/caucasian and this sample recorded $97.6 \%$ of participants as falling in the same category. The sample set demonstrated slightly more racial diversity than the census, with $2.4 \%$ of the sample identifying as persons of color/nonwhite. The mixed-methods approach provided a textured view of the data, corroborating the findings. The survey questions followed the hypothesis that the geographical density of churches in an area with a smaller population could provide a service-enhancing partnership for mental health care. Thus, questions probed into residents' preferences for church/mental health partnerships. The mixed-methods approach incorporating focus groups added deeper layers to this information and allowed the community to participate more in the study and in the crafting of the community recommendations. The overall participatory nature of this research study and ensuing community-task force is a strength of the study.

\section{Limitations}

This study encountered limitations due to the purposive and snowball sampling method employed by the researchers. While this method easily accessed those already wellconnected in the community, these individuals were often community leaders, more educated, and higher paid than the broader Martin County census data reflect. Overall sample demographics reflect more female participants, individuals with a higher education level and higher annual household income, as well as fewer individuals aged 65 or older. The majority of participants in the study were female $(82 \%)$ while the US Census Bureau reports that $49 \%$ of the county is female (2018). Similarly, over $50 \%$ of participants held a bachelor's degree or higher, compared to only $13.4 \%$ of county residents (US Census Bureau 2018).

Additionally, Martin County lacks key spaces—-such as YMCAs, homeless shelters, or community centers - which may broaden the sample demographic in urban/suburban areas. The lack of technology equity within the county also limited the study. Online survey distribution and focus group recruitment were limited due to diminished broadband and internet connectivity in the area. Focus group participants were recruited through the same means as the survey, as well as snowball recruitment through confirmed participants. Further, researchers were limited to Christian-based church partnerships, as there are no other institutional faith communities located within the county. The following seven 
implications for community mental health practice and research were revealed based upon this study and the reflection of its processes-successful or otherwise.

\section{Become an Ethnographer}

As informed by Daley (2015), working within a rural community is a learning experience, as culture varies within and between rural populations. In order to learn and provide culturally competent care, community mental health workers must engage with and immerse themselves in the local culture. Accessible ways to do this include asking questions, such as: what makes this culture unique (i.e. food, music, festivals), who holds the power, what do residents love about their town, what stories are shared between the residents, how has the environment and topography shaped the community, how was the town settled and by whom, and how does all of this contribute to the community seen today? Rural communities often expect workers to adapt to them (Daley 2015) and thus becoming an ethnographer is a step towards developing this important cultural competency.

\section{Connect the Service Providers}

In Martin County, many dedicated individuals invested in their community were left under-unified and with no clear mental health network. In Martin County and similar rural communities, bringing these individuals together could not only amplify their individual work, but provide synchronicity for a more deep-reaching community impact.

\section{Being an Outsider is an Asset}

Mental health service providers living outside the community have an extremely important role to play in rural communities. Being an outsider promotes more vulnerability from the local residents, increasing anonymity and decreasing stigma. Yet it is a double-edged sword: while outsider status provides anonymity rural mental health workers must understand the systems and nuances of the community, which further emphasizes the recommendation to become a local ethnographer.

\section{Relationships are the Keys to the Community}

Mental health professions center around human connection, which is especially advantageous in rural communities. Personal relationships prove crucial for building trust with individuals in the community and gaining access to the community's knowledge and/or power. Often extremely important and profound pieces of information emerge when the research agenda is side-lined in favor of truly listening to someone talk.

\section{Be Strengths-Based}

If the problems are in the community, so are the solutions (Slone et al. 2019). Take time to consider what is already working. While an innovative silver-bullet that eradicates all problems might be possible, it is more likely that the community will be best served by expanding something already working well in the community. By adopting this approach, the community is pushed to build and expand its capacity for using these modalities to reach more people with services.

\section{Mental Health Workers as Educators}

Mental health workers wear many hats and play various roles, one of which is that of an educator. Mental health workers must assume the duty to educate not only themselves on innovative technologies and evidence-based practices, but also clients, communities, and integrated systems. In addition to introducing communities to cutting-edge technologies and evidence-based practice, mental health workers can also link residents to underutilized services as well as linking providers to each other and their resources. As a focus group member said, "How can they know unless they are told? They have to be told."

\section{Broadband Internet Advocacy}

In the 1930s, rural communities lagged behind the quickly industrialized world because nine out of ten homes were still without electricity. Forced into pre-industrial agricultural practices, residents were forced to farm for little profit in the mechanized world (NRECA 2019). Rural residents toiled and organized to cooperatively bring electric service to rural areas, preserving their livelihood and opening the doors to progress in their communities. Today this social justice issue echoes in activism surrounding broadband internet in rural areas. It is now time to organize, cooperate, and deliver broadband internet to areas being left behind in health, economics, and opportunities by this damaging technological deficit.

Acknowledgements This study was approved by the Indiana University Institutional Review Board, protocol \#1904634076A002. 


\section{Appendix}

\section{Appendix A: Mental Health Survey}

\section{Appendix A: Mental Health Survey}

\section{Mental Health Service Delivery in Martin County}

Your responses to this survey are completely anonymous and will only be used for the purposes of this research study. Your participation is voluntary and you may stop taking this survey at any time. Please do not put your name on this form! This survey has been approved by the Institutional Review Board at IUB, and will be used to help understand how to improve access to mental health services for the Martin County area. Please feel free to contact Dr. Carol Hostetter if you have any questions, at 812-855-4427 or chostett@indiana.edu.

We appreciate your feedback!

* $\quad$ Required

Residency

1. Are you over the age of $18 *$

Mark only one oval.

Yes

No After the last question in this section, stop filling out this form.

2. Are you a current resident of Martin County, Indiana? *

Mark only one oval.

Yes

No Stop filling out this form. 
Demographics

3. What is your gender?

Mark only one oval.

Female Male

Prefer not to answer

4. How old are you?

Mark only one oval.

$18-25$

26-39

$40-65$

$65+$

5. What is your race/ethnicity?

Mark only one oval.

White/Caucasian

Non-white/mixed race/mixed ethinicity Prefer not to answer

6. What is the highest level of schooling that you have completed?

Mark only one oval.

Less than high school diploma

High school graduate, diploma or the equivalent (i.e. GED, HSE) Some college credit, no degree

Trade/technical/vocational training Associate degree

Bachelor's degree Graduate/professional degree Prefer not to answer

7. What is your employment status? (check all that apply)

Check all that apply.

Employed for wages Self-employed

Out of work and looking for work

Out of work but not currently looking for work Employed without documentation

A homemaker A student Military Disability/SSI

Unable to work/Other

8. What is your household's annual income level?

Mark only one oval.

$0-\$ 20,000$

$\$ 20,001-50,0000$

$\$ 50,001-\$ 80,000$

$\$ 80,001-\$ 100,000$

Over $\$ 100,000$ Prefer not to answer

9. Are you a pastor/minister/member of the clergy?

Mark only one oval.

Yes No

10. How often do you attend church or church programming in Martin County? Mark only one oval. 
At least once a week A few times per month Once a month

A few times a year Never

Prefer not to answer

Mental health questions

11. Do you or have you ever had difficulty completing activities of daily living (caring for yourself, caring for Mark only one oval. others, work responsibilities, etc) due to your mental health?

Yes No

Prefer not to answer

12. Have you ever sought mental health services/counseling for yourself while living in Martin County? Mark only one oval.

Yes $\quad$ Skip to question 13. No Skip to question 18. Prefer not to answer

If YES to previous engagement

13. Were these services located in Martin County, IN?

Mark only one oval.

Yes No

14. Please select what types of services you have engaged with (select all that apply)

Check all that apply.

Individual therapy/counseling Group therapy

Family therapy/counseling Life skills coaching Pastoral Care

Self Help Groups Other

15. If you answered other to the previous question, please specify:

16. On a scale of $1-5$, how satisfied were you with the quality of service you received?

(If multiple mental health services were used, please consider the one you used for the longest amount of time.) Mark only one oval.

$\begin{array}{lllll}1 & 2 & 3 & 4 & 5\end{array}$

Not satisfied at all $\quad$ Extremely satisfied

17. On a scale of 1-5 how satisfied were you with the distance you had to travel to receive services?

(If multiple mental health services were used, please consider the one you used for the longest amount of time.) Mark only one oval.

$\begin{array}{lllll}1 & 2 & 3 & 4 & 5\end{array}$

Not satisfied at all Extremely satisfied

Skip to question 18. 
Whether or not you have engaged with mental health services, to what degree are the following factors a barrier to accessing services?

18. Availability of services

Mark only one oval.

$\begin{array}{lllll}1 & 2 & 3 & 4 & 5\end{array}$

not a barrier significant barrier

19. Insurance (ex. had no insurance, insurance wouldn't cover the treatment cost, etc.) Mark only one oval.

$\begin{array}{lllll}1 & 2 & 3 & 4 & 5\end{array}$

not a barrier significant barrier

20. Financial resources (ex. treatment was too expensive) Mark only one oval.

$\begin{array}{lllll}1 & 2 & 3 & 4 & 5\end{array}$

not a barrier significant barrier

21. Knowing where to find help (ex. didn't know about local treatment facilities, services, etc.) Mark only one oval.

$\begin{array}{lllll}1 & 2 & 3 & 4 & 5\end{array}$

not a barrier significant barrier

22. Family/child care (ex. had no one to take care of family members and/or children) Mark only one oval.

$\begin{array}{lllll}1 & 2 & 3 & 4 & 5\end{array}$

not a barrier significant barrier

23. Time commitment (ex. time away from job, family, friends, etc.) Mark only one oval.

$\begin{array}{lllll}1 & 2 & 3 & 4 & 5\end{array}$

not a barrier significant barrier

24. Transportation (ex. could not get to treatment) Mark only one oval.

$\begin{array}{lllll}1 & 2 & 3 & 4 & 5\end{array}$


not a barrier significant barrier

25. Stigma (ex. unsure if treatment will work, worries about what other people think, fear of failure, bad experience with treatment in the past, etc.)

Mark only one oval.

\begin{tabular}{ccccr}
1 & 2 & 3 & 4 & 5 \\
not a barrier & & \multicolumn{2}{l}{ significant barrier }
\end{tabular}

Skip to question 26.

Church/Mental health Partnerships

On a scale of 1-5, how likely would you be to seek help from the following? 1 - extremely unlikely

2 - not likely 3 - neutral

4 - likely

5- extremely likely

If needed now or ever in the future, how likely would you be to seek mental health help from:

26. A mental health counselor located outside Martin County referred to you by a trusted pastor/minister/clergy Mark only one oval.

$\begin{array}{lllll}1 & 2 & 3 & 4 & 5\end{array}$

Extremely unlikely Extremely likely

27. A counselor on staff at a church in Martin County

Mark only one oval.

$\begin{array}{lllll}1 & 2 & 3 & 4 & 5\end{array}$

Extremely unlikely Extremely likely

28. A counselor from outside the county who you meet with inside a local church space

Mark only one oval.

$\begin{array}{lllll}1 & 2 & 3 & 4 & 5\end{array}$

Extremely unlikely $\quad$ Extremely likely

29. A Bible study or small group at a church that teaches mental health skills and coping strategies Mark only one oval.

$\begin{array}{lllll}1 & 2 & 3 & 4 & 5\end{array}$

Extremely unlikely $\quad$ Extremely likely

30. A self-help group comprised of other Martin County residents

Mark only one oval. 


$\begin{array}{lrrrr}1 & 2 & 3 & 4 & 5 \\ \text { Extremely unlikely } & & \text { Extremely likely }\end{array}$

31. A trained volunteer from Martin County who helps you with goals and strategies for mental health Mark only one oval.

$\begin{array}{lrrrr}1 & 2 & 3 & 4 & 5 \\ \text { Extremely unlikely } & & \text { Extremely likely }\end{array}$

32. A counselor who works with you and a trusted pastor/minister in Martin County Mark only one oval.

\begin{tabular}{llrll}
1 & 2 & 3 & 4 & 5 \\
Extremely unlikely & & \multicolumn{2}{l}{ Extremely likely }
\end{tabular}

33. A counselor who you meet with via internet in a private space inside a local church Mark only one oval.

$\begin{array}{lrrrr}1 & 2 & 3 & 4 & 5 \\ \text { Extremely unlikely } & & \text { Extremely likely }\end{array}$

\section{Appendix B: Focus Group Interview Guide}

Questions based on survey:

1. What does Mental Health mean to you? Eg. when someone says mental health services, what do you think of?

2. How are people in Martin County getting their mental health needs met?

a. Based on our survey results thus far, we are seeing that the majority of people who sought mental health services were not receiving these services in Martin County. $81 \%$ of these people were either neutral or satisfied with these services. $71 \%$ were dissatisfied or extremely dissatisfied with the distance they had to travel. Does anyone have any thoughts on that?

3. We want to touch on some barriers to services that were prominent in our results, such as availability of services, financial resources, and stigma. Are there are others that people feel we should know about or further explore?

a. Availability of services: The vast majority of individuals noted that availability of services serve as a barrier to individuals accessing mental health services. Can you tell us more about that? b. Financial resources: More than half of our respondents indicated that financial resources were a barrier to seeking mental health services. Can you tell us more about that? What are the conditions like in Martin County that may be leading to these responses? Cost of care? (what is it?) Well paying jobs? (are there any?)

c. Stigma: maybe offer a basic definition of stigma, ask how people in Martin County experience that? What does stigma look like in Martin County?

4. As mentioned earlier, people indicated that they were not satisfied with the distance they had to travel to receive care. However, the majority of people then said they would be likely to seek health from a counselor located outside of the county, referred by a trusted member of the church community. Can anyone speak more to that? (a willingness to travel if referred to by the church maybe?)

5. Approximately $80 \%$ of our respondents indicated they were either neutral or likely to meet inside a church space with a counselor from outside the county. Can you tell us more about this? 
6. Almost $70 \%$ of people said they were not likely to want to meet with a self-help group comprised of other Martin County residents. Can anyone speak to this?

7. The majority of our respondents did not seem likely to want to meet with a counselor over the internet in a space inside a church. Tell us more about this. Does this have to do with the internet/telehealth piece or the meeting space? Does education about/access to technology play a role?

So from what we've talked about today, it seems like (sum up key points/themes). Is there any other information we need to know about mental health services in Martin County?

\section{Appendix C: Focus Group Participants' Written Responses to Survey-Identified Mental Health Service Delivery Models}

\section{MEET WITH A SELF-HELP GROUP WITH MARTIN COUNTY RESIDENTS:}

Good support group option, but not for the only mental health services.

Use only as a support or aftercare.

Best if used as support.

This option may help a few but for the most part, many people need services from professionals.

This option for anyone wanting to live, basically as primary motivation, is better than relying upon the "street wisdom"; emphasis should be placed by the coordinator to the group upon scriptural wisdom (Divine Revelation); recommendations I know are helpful to me are Psalm 139; Psalm 73; Psalm 27; New Testament; St Paul; (Denying oneself and "carrying one's cross"); Matthew 10 \& 16; Mark 8; \& Luke 9.

\section{MEET WITH A COUNSELOR OUTSIDE MARTIN COUNTY REFERRED BY A PASTOR/CHURCH}

Pro: if you are familiar with the pastor and had a good relationship.

Con: perhaps you feel pressured to go based on that recommendation.

This would be great if they already have a relationship with said pastor. Otherwise, anyone who they trust.

It would be a good option for those who want another outside of the county option.

SOme people don't have relationships with their pastors.

Good option for those that have a good relationship with pastor.
MEET WITH A COUNSELOR VIA INTERNET WITHIN A CHURCH SPACE

Possibly could work if you feel there is more anonymity.

The church can be a viable support and resource for those in need. This option could shed a positive light on some that many have had a bad "church" experience and there are hurt feelings due to a situation. God is good-let him work in and through the local churches!

Offers more availability.

Not personal enough for most.

Sign us up if everyone has access [internet].

\section{MEET WITH A COUNSELOR FROM OUTSIDE THE COUNTY BUT WITHIN A CHURCH SPACE IN MARTIN COUNTY}

Pro: church may feel like a safe place if they are familiar with it.

Con: some may have had a poor experience at a church or religious setting.

May be too traumatic for some people to meet in a church space where it may be comfortable for others. Also, many seek a "health care" setting to meet a professional.

Feel comfortable wherever they are.

Sounds good if they are unknown at initial meeting.

Great option as long as there is a non-faith-based location offer as well.

\section{References}

Alford, K. A., Cook, J. F., \& Conway, P. (2012). Conclusion: Rural families, another element in the mosaic of diversity. Journal of Family Social Work, 15(5), 461-463. https://doi.org/10.1080/10522 158.2012 .721120

Baffour, T. D. (2011). Addressing health and social disparities through community-based participatory research in rural communities: Challenges and opportunities for Social Work. Contemporary Rural Social Work Journal, 3(1), 3. Retrieved September 16, 2019 from https://digitalcommons.murraystate.edu/crsw/vol3/iss1/3.

Bolin, J. N., Bellamy, G. R., Ferdinand, A. O., Vuong, A. M., Kash, B. A., Schulze, A., \& Helduser, J. W. (2015). Rural healthy people 2020: New decade, same challenges. The Journal of Rural Health, 31(3), 326-333.

Brocious, H., Eisenberg, J., York, J., Shepard, H., Clayton, S., \& Van Sickle, B. (2013). The strengths of rural social workers: Perspectives on managing dual relationships in small Alaskan communities. Journal of Family Social Work, 16, 4-19. https://doi. org/10.1080/10522158.2012.745180

Castillo, E. G., Ijadi-Maghsoodi, R., Shadravan, S., Moore, E., Mensah, M. O., 3rd., Docherty, M., et al. (2019). Community interventions to promote mental health and social equity. Current Psychiatry Reports, 21(5), 35. https://doi.org/10.1007/s11920-019-1017-0

Clark, T. R., Freedman, S. B., Croft, A. J., Dalton, H. E., Luscombe, G. M., Brown, A. M., et al. (2013). Medical graduates becoming rural doctors: Rural background versus extended rural placement. The Medical Journal of Australia. https://doi.org/10.5694/mja13 .10036 
Cunningham, B. J., Merwe, R. V. (2009). Virtual grand rounds: A new educational approach in social work that benefits long-term care providers and patients in rural Idaho. Rural and Remote Health, 9(1).

Daley, M. R. (2015). Rural social work in the 21st Century. New York: Oxford University Press.

Edwards, M. E., Torgerson, M., \& Sattem, J. (2009). Paradoxes of providing rural social services: The case of homeless youth. Rural sociology, 74(3), 330-355.

Faulkner, S. S., \& Faulkner, C. A. (2018). Research methods for social work: A practice-based approach (2nd ed.). New York: Oxford University Press.

Get Schooled Tour. (2018). [Participant survey] [Unpublished raw data]. Get Schooled Tour: Martin County, IN.

Glaser, B. G., \& Strauss, A. L. (1967). The discovery of grounded theory: Strategies for qualitative research. Chicago: Aldine Publishing.

Griffin, D., \& Farris, A. (2010). School counselors and collaboration: Finding resources through community asset mapping. Professional School Counseling, 13(5), 2156759X1001300501.

Heflin, C., \& Miller, K. (2012). The geography of need: Identifying human service needs in rural America. Journal of Family Social Work, 15(5), 359-374. https://doi.org/10.1080/10522 158.2012.719476

Hoeft, T. J., Fortney, J. C., Patel, V., \& Unützer, J. (2018). Task-sharing approaches to improve mental health care in rural and other low-resource settings: A systematic review. The Journal of Rural Health, 34(1), 48-62.

Humble, M. N., Lewis, M. L., Scott, D. L., \& Herzog, J. R. (2013). Challenges in rural social work practice: When support groups contain your neighbors, church members, and the PTA. Social Work with Groups, 36(2-3), 249-258. https://doi. org/10.1080/01609513.2012.753807

Indiana Youth Institute. (2020). Martin County. 2020 Indiana KIDS COUNT DATA BOOK. Retrieved February 25, 2020 from https ://iyi-website.s3.amazonaws.com/data-book/2020+Snapshots+/ Snapshots/Martin.pdf.

Kazdin, A. E. (2017). Addressing the treatment gap: A key challenge for extending evidence-based psychosocial interventions. Behaviour Research and Therapy, 88, 7-18.

Keeler, H., Sjuts, T., Niitsu, K., Watanabe-Galloway, S., Mackie, P.F.E., \& Liu, H. (2018). Virtual mentorship network to address the rural shortage of mental health providers. American Journal of Preventive Medicine, 54, S290-S295. https://doi.org/10.1016/j. amepre.2018.02.001

Keesler, J. (2014). Trauma through the lens of service coordinators: Exploring their awareness of adverse life events among adults with intellectual disabilities. Advances in Mental Health and Intellectual Disabilities, 8(3), 151-164. https://doi.org/10.1108/ AMHID-04-2013-0028

Kitchener, S., Day, R., Faux, D., Hughes, M., Koppen, B., Manahan, D., et al. (2015). Longlook: Initial outcomes of a longitudinal integrated rural clinical placement program. The Australian journal of rural health. https://doi.org/10.1111/ajr.12164

McPherson, K. M., Kayes, N. K., Moloczij, N., \& Cummins, C. (2014). Improving the interface between informal carers and formal health and social services: A qualitative study. International Journal of
Nursing Studies, 51(3), 418-429. https://doi.org/10.1016/j.ijnur stu.2013.07.006

National Association of Social Workers. (2019). NASW code of ethics. Retrieved September 2, 2019 from https://www.socialworkers.org/ About/Ethics/Code-of-Ethics/Code-of-Ethics-English.

National Rural Electric Cooperative Association (NRECA). (2019). History: The story behind America's electric cooperatives and NRECA. Retrieved September 23, 2020 from https://www.elect ric.coop/our-organization/history.

Olson, C. J. (2011). Foot soldiers for social justice: Realities, relationships, and resilience. Contemporary Rural Social Work, 3(1), 4-16. Retrieved September 12, 2019 from https://searc h-ebscohost-com.proxyiub.uits.iu.edu/login.aspx?direc $\mathrm{t}=$ true $\& \mathrm{db}=\mathrm{swh} \& \mathrm{AN}=82975 \&$ site $=$ ehost-live \&scope $=$ site.

Puffer, E. S., Green, E. P., Sikkema, K. J., Broverman, S. A., OgwangOdhiambo, R. A., Pian, J. (2016). A church-based intervention for families to promote mental health and prevent HIV among adolescents in rural Kenya: Results of a randomized trial. Journal of Consulting and Clinical Psychology, 84(6), 511-525. https:// doi.org/10.1037/ccp0000076.

Rural Health Information Hub. (2020). Barriers to mental health treatment in rural areas. Retrieved February 24, 2020 from https:// www.ruralhealthinfo.org/toolkits/mental-health/1/barriers.

Saleeby, D. (1992). The strengths perspective in social work practice. White Plains, NY: Longman.

Slone, M., Feltner, F., Bowling, B. (2019) Building Capacity for Community-based Participatory Research (CBPR): Successful Strategies. Presentation at the meeting of the National Institute of Social Work and Human Services in Rural Areas, Paducah, KY.

Strand, K., Marullo, S., Cutforth, N., Stoecker, R., \& Donohue, P. (2003). Community-based research and higher education. San Francisco: Jossey-Bass.

Sun, F. (2011). Community service use by older adults: The roles of sociocultural factors in rural-urban differences. Journal of Social Service Research, 37(2), 124-135. https://doi.org/10.1080/01488 376.2011 .547446

US Census Bureau. (2018). Quick facts: Martin County, Indiana. Retrieved September 18, 2019 from https://www.census.gov/quick facts/martincountyindiana.

Voss, S. L. (1996). The church as an agent in rural mental health. Journal of Psychology \& Theology, 24(2), 114-123. https://doi. org/10.1177/009164719602400204.

Walsh, W. A., \& Mattingly, M. (2012). Understanding child abuse in rural and urban America: Risk factors and maltreatment substantiation (Issue brief no. 50). Carsey Institute/University of New Hampshire. Retrieved October 1, 2019 from https://scholars.unh. edu/cgi/viewcontent.cgi?article $=1169 \&$ context $=$ carsey.

Waltman, G. H. (2011). Reflections on rural social work. The Journal of Contemporary Social Services, 92(2), 236-239. https://doi. org/10.1606/1044-3894.409

Publisher's Note Springer Nature remains neutral with regard to jurisdictional claims in published maps and institutional affiliations. 